\title{
Association of HLA-A3 and HLA-B14 antigens with idiopathic haemochromatosis
}

\author{
M. SIMON'1, M. BOUREL, R. FAUCHET, AND B. GENETET \\ From the Clinique Médicale A, Unité de Recherche U 49 (INSERM), and Centre Régional de \\ Transfusion Sanguine, Hôpital Pontchaillou, Rennes, France
}

SUMMARY The frequency of HLA-A3 and HLA-B14 antigens was significantly higher in a series of 51 patients with idiopathic haemochromatosis than in a control group, being respectively 78.4 versus $27.0 \%$ and 25.5 versus $3.4 \%$. This finding strongly supports the suggestion that idiopathic haemochromatosis is a genetic disease and suggests that the gene(s) responsible for the disease may be linked to the histocompatibility genes.

The aetiology of idiopathic haemochromatosis (IH) is controversial, most authors regarding this affection as an inborn error of metabolism (Sheldon, 1935), while others consider it to be an acquired disease (MacDonald, 1964). In this paper, we report the results of the determination of histocompatibility antigens in a series of patients with IH. The investigation showed a significant association of HLA-A3 and HLA-B14 antigens with IH, a finding which strongly supports the notion of hereditary transmission of the disease.

\section{Methods}

\section{PATIENTS}

Fifty-one patients having no family ties, 46 male (mean age: $42 \cdot 2$ years, range: $26-62$ ) and five female (mean age: 53.4 years, range: 46-61) with unequivocal IH were studied. Skin pigmentation and hepatomegaly were present in all of them, diabetes mellitus in 43, gonadal deficiency in 42 , heart failure in 13 . Serum iron was $35 \mu \mathrm{mol} / 1$ or more, and unsaturated iron binding capacity was $10 \%$ or less in all the patients. Stainable iron was demonstrated in the liver specimens from the 49 biopsied patients; in the two non-biopsed patients the desferrioxamine test (1.5 $\mathrm{g}$ infused intravenously for four hours) was markedly abnormal with urinary iron excretion of 10290 and $18760 \mu \mathrm{g} 24 \mathrm{~h}$ (normal: less than 2000 $\mu \mathrm{g} 24 \mathrm{~h})$. The control group consisted of 204 apparently normal adult blood donors.

1Address for reprint requests: M. Simon, Clinique Medicale A, Hopital Pontchaillou, 35043 Rennes Cedex, France.

Received for publication 23 January 1976
Only two pairs of linked alleles, A and B according to the new nomenclature (WHO-IUIS Terminology Committee, 1975) were investigated. The antigens determined by these genes were typed on lymphocytes according to the method of Dausset (Dausset, 1973) and/or on platelets according to the method of Colombani et al. (Colombani et al., 1973), using the sets of antisera provided by the Laboratoire National de Référence (Département d'Immunologie, Hôpital Saint-Louis, Paris).

The percentages of the different antigens in the patients with $\mathrm{IH}$ and in the controls were compared by means of the $\chi^{2}$ test or Fisher's exact test (Siegel, 1956). The usual correction for multiple comparisons was made by multiplying the level of significance thus found for each test by the total number of antigens considered.

\section{Results}

The results of the typing and their statistical significance are set out in Table 1: it appears that two antigens, and only two, according to the corrected level of significance, HLA-A3 and HLA-B14, had a significantly higher prevalence in the IH patients than in the controls. The association of HLA-A3 and HLA-B14 was likewise more frequent in the IH patients than in the controls, in whom this association was remarkably uncommon (Table 2).

\section{Discussion}

Thus, there is a significant association of HLA-A3 and HLA-B14 antigens with IH; the present results confirm our preliminary findings based on a 


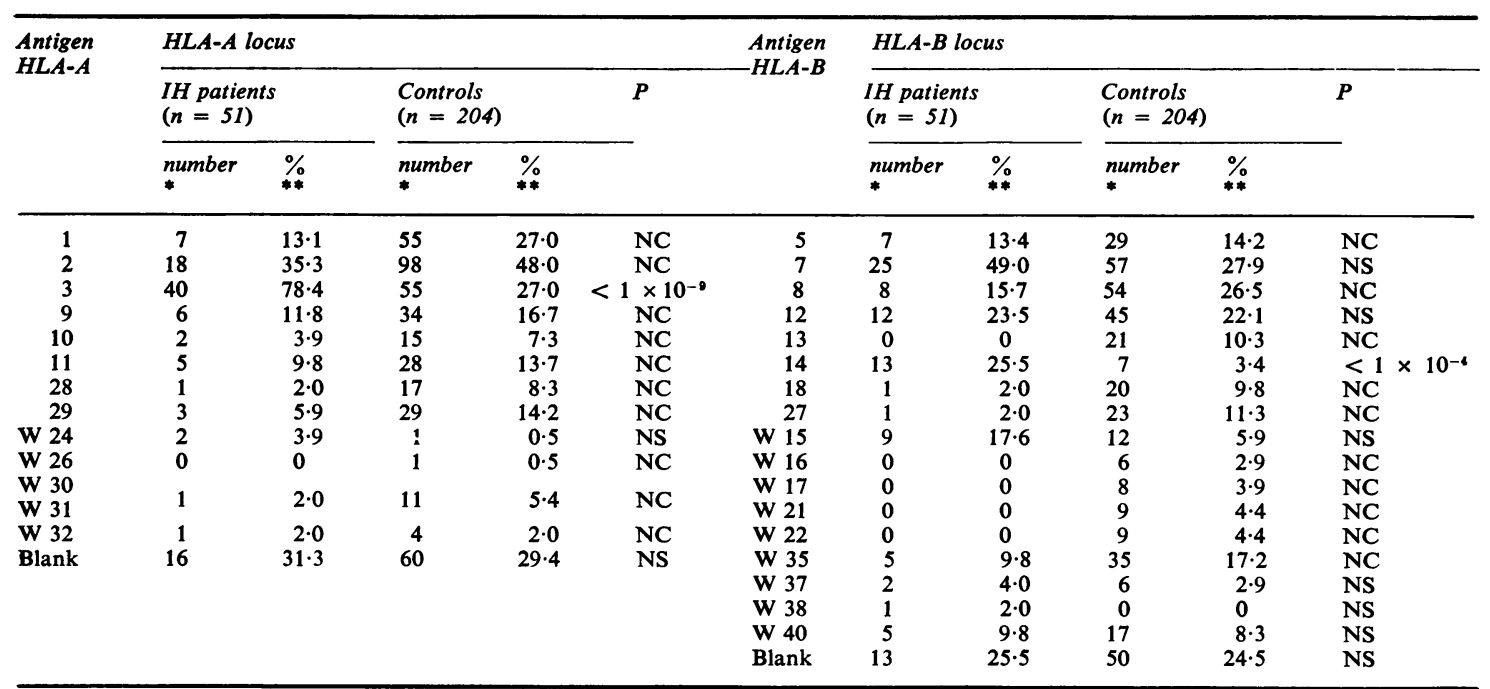

Table 1 Distribution of histocompatibility antigens in patients with idiopathic haemochromatosis $($ IH) and in controls

${ }^{*}$ Total $=2 \mathrm{n}$ (two antigens per locus); **total $=200 \% ; \mathrm{NC}=$ not calculated (lower frequency of the antigens in IH patients than in controls, as a direct consequence of higher frequency of HLA-A3 or HLA-B14); NS = not significant (with corrected P).

\begin{tabular}{|c|c|c|c|c|}
\hline \multirow[t]{2}{*}{ Allele associations } & \multicolumn{2}{|c|}{$I H$ patients $(n=5 I)$} & \multicolumn{2}{|c|}{ Controls $(n=204)$} \\
\hline & no. & $\%$ & no. & $\%$ \\
\hline \multicolumn{5}{|l|}{ HLA A-B } \\
\hline HLA-A3 - HLA-B14 & 12 & $23 \cdot 5$ & 2 & $1 \cdot 0$ \\
\hline HLA-A3 - HLA-BW15 & 8 & $15 \cdot 7$ & 3 & $1 \cdot 5$ \\
\hline HLA-A3 - HLA-B7 & 20 & $39 \cdot 2$ & 21 & $10 \cdot 3$ \\
\hline \multicolumn{5}{|l|}{ HLA A-A } \\
\hline HLA-A3 - different antigens & 27 & $52 \cdot 9$ & 43 & $21 \cdot 1$ \\
\hline HLA-A3 - blank & 13 & $25 \cdot 5$ & 12 & $5 \cdot 9$ \\
\hline
\end{tabular}

Table 2 Frequency of certain allele associations in patients with idiopathic haemochromatosis and in controls

small number of patients with IH (Genetet et al., 1975; Simon et al., 1975). Therefore, IH is an additional instance of association between histocompatibility antigens and diseases (Dausset et al., 1974; Svejgaard et al., 1975). However, the association of HLA-A3 and HLA-B14 with IH is remarkable for the following reasons: (1) the association of HLAA3 is close, reaching the same order of magnitude as that of HLA-B27 antigen with ankylosing spondylitis (Brewerton et al., 1973; Schlosstein et al., 1973); (2) one of the antigens associated with IH belongs to the HLA-A locus, whereas most of the antigens associated with other diseases belong to the HLA-B locus; (3) most of the diseases associated with histocompatibility antigens are more or less related to disorders of immunity, whereas IH is apparently unrelated to this type of disorder.

Although most authors accept that $\mathrm{IH}$ is an inborn error of iron metabolism (Sheldon, 1935), some have questioned the genetic transmission of the disease and suggested that $\mathrm{IH}$ is an acquired disorder (MacDonald, 1964). Our finding that IH is associated with certain histocompatibility antigens represents a strong argument in favour of the genetic origin of $\mathrm{IH}$, although the adjuvant role of environmental factors cannot be excluded. The histocompatibility alleles themselves might be directly implicated in the transmission of IH; however, the discrepancy between the relatively high frequency of HLA-A3 antigen in the normal population and the relatively low frequency of IH makes this hypothesis unlikely. An alternative hypothesis might be that the gene(s) responsible for IH would be linked to the histocompatibility alleles; in this case, the gene(s) for IH would be located on chromosome 6 , to which the major histocompatibility complex is assigned (Lamm et al., 1975), close to the HLA-A locus. With respect to the mode of inheritance of IH, the observation that iron overload is significantly more frequent (Alexandre, 1975) in 
the siblings than in the offspring is hardly compatible with the hypothesis of a monogenic dominant pattern (Alexandre, 1975; Saddi and Feingold, 1974). Likewise, a monogenic recessive pattern (Saddi and Feingold, 1974) is not satisfactory for the following reason: the heterozygous state for HLA-A3, and therefore for the gene(s) for IH which would be linked with it, is present in up to $53 \%$ of the patients, the frequency of possible homogozygosity $(25.5 \%)$ being frankly lower (Table 2).

Finally, a plausible hypothesis might be that IH is inherited according to a polygenic pattern, or, more probably, an oligogenic pattern, since the HLA alleles or the gene(s) linked with them play a predominant role; the high frequency of $\mathrm{IH}$ over one generation might result from an interaction effect.

The incidence of $\mathrm{IH}$ is remarkably high in Brittany. Our finding of the association of certain histocompatibility antigens with IH might be peculiar to the form of IH observed in Brittany. Observations in patients with IH from other geographical areas are needed to extend the concept of association of certain histocompatibility antigens to all the patients suffering from the disease.

We are indebted to Association France-Transplant for providing the antisera.

\section{References}

Alexandre, J-L. (1975). Etude de l'Hérédité dans l'Hémochromatose, à Propos de 106 Enquêtes Familiales. Thesis: Rennes.

Brewerton, D. A., Caffrey, M., Hart, F. D., James, D. C. O., Nicholls, A., and Sturrock, R. D. (1973). Ankylosing spondylitis and HL-A 27. Lancet, 1, 904-907.

Colombani, J., D’Amaro, J., Gabb, B., Smith, G., and
Svejgaard, A. (1973). Micro-technique of platelet complement fixation. In Manual of Tissue Typing Techniques, pp. 69-74. Edited by J. G. Ray, D. B. Hare, and D. E. Kayhoe. (DHEW Publication No. (NIH) 74-545): Bethesda, Maryland.

Dausset, J. (1973). Micro-lymphocytotoxicity technique. In Manual of Tissue Typing Techniques, pp. 28-33. Edited by J. G. Ray, D. B. Hare, and D. E. Kayhoe. (DHEW Publication No. (NIH) 74-545): Bethesda: Maryland.

Dausset, J., Degos, L., and Hors, J. (1974). The association of the HL-A antigens with diseases. Clinical Immunology and Immunopathology, 3, 127-149.

Genetet, B., Genetet, N., Fauchet, R., Pawlotsky, Y., Oger, J., Simon, M., and Bourel, M. (1975). HL-A antigens and diseases. In Book of Abstracts of the XIV Congress of the International Society of Blood Transfusion, p. 37. Finnish Red Cross Blood Transfusion Service: Helsinki.

Lamm, L. U., Thorsen, I-L., Petersen, G. B., Jørgensen, J., Henningsen, K., Bech, B., and Kissmeyer-Nielsen, F. (1975). Data on the HL-A linkage group. Annals of Human Genetics, 38, 383-390.

MacDonald, R. A. (1964). Hemochromatosis and Hemosiderosis. Thomas: Springfield, Ill.

Saddi, R., and Feingold, J. (1974). Idiopathic haemochromatosis: an autosomal recessive disease. Clinical Genetics, 5, 234-241.

Schlosstein, L., Terasaki, P. I., Bluestone, R., and Pearson, C. M. (1973). High association of an HL-A antigen, W 27, with ankylosing spondylitis. New England Journal of Medicine, 288, 704-706.

Sheldon, J. H. (1935). Haemochromatosis. Oxford University Press: London.

Siegel, S. (1956). Nonparametric Statistics for the Behavioral Sciences, MacGraw-Hill: New York.

Simon, M., Pawlotsky, Y., Bourel, M., Fauchet, R., and Genetet, B. (1975). Hémochromatose idiopathique. Maladie associée à l'antigène tissulaire HL-A3 ? Nouvelle Presse Médicale, 4, 1432.

Svejgaard, A., Platz, P., Ryder, L. P., Staub Nielsen, L., and Thomsen, M. (1975). HL-A and disease associations-a survey. Transplantation Review, 22, 3-43.

WHO-IUIS Terminology Committee (1975). Nomenclature for factors of the HLA system. In Proceedings of the Sixth International Histocompatibility Workshop Conference. Munksgaard: Copenhagen. (in press). 